\title{
Jogo da "trilha ecológica capixaba": uma proposta pedagógica para o ensino de ciências e a educação ambiental através da ludicidade
}

Leonardo Salvalaio Muline

Adriane Gonçalves Gomes

Manuella Villar Amado

Carlos Roberto Pires Campos

\section{Resumo}

Atividades escolares que buscam a Educação Ambiental devem ser capazes de melhorar a compreensão do meio ambiente, promovendo a alteração dos comportamentos dos alunos para com seu ambiente e as próprias relações interpessoais. Quando se fala na modificação do comportamento, os jogos têm papel fundamental. Desta forma, este trabalho teve por objetivo o desenvolvimento e a avaliação de um jogo didático intitulado "Trilha Ecológico Capixaba" baseado na realidade dos alunos, comprometido com o ensino de Ciências e com a transformação socioambiental. O jogo foi aplicado em uma turma do sexto ano do ensino fundamental da Escola Municipal Marieta Escobar, localizada no bairro Santa Martha, no município de Vitória (ES). Trata-se de um estudo de práticas pedagógicas, desenvolvido com abordagem qualitativa, construído a partir de observações dos autores dentro de uma perspectiva fenomenológica. Os resultados indicam que o jogo desenvolvido obteve resultados satisfatórios enquanto instrumento motivador do aprendizado, trazendo benefícios na construção, desconstrução e reconstrução dos conhecimentos por parte das crianças, capaz de romper paradigmas sobre as concepções de meio ambiente. Desta forma, acredita-se que o jogo "Trilha Ecológica Capixaba" é uma atividade pedagógica lúdica capaz de modificar a concepção dos alunos de meio ambiente para uma perspectiva mais multidimensional, que considera o meio ambiente como um sistema complexo, sensibilizando o educando de forma que valorize mais o ambiente em que vive.

Palavras-chave: Jogo pedagógico, Ensino de ciências, Educação ambiental, Metodologias lúdicas.

\footnotetext{
Abstract

School activities that seek environmental education should improve a social understanding of the environment, promoting changes in attitudes of students towards their environment and their own relationships. If we desire a behavior change the educative games play a fundamental role. Thus, this study aimed at discussing both the development and the evaluation of an educational game entitled "Capixaba Ecological Trail" based on the reality of students committed to science education and the social and environmental transformation. The game was applied to a class of sixth year of the public elementary school Marietta Escobar, located in Vitória (ES). The research consists of a study of pedagogical practices, on a qualitative approach, built from observations of the authors within a phenomenological investigation. The results indicate that the game developed achieved satisfactory results while motivating learning tools,
} 
bringing benefits in the construction, deconstruction and reconstruction of knowledge concerning to the children ecological behavior, in order to break paradigms on the concepts of environment. Thus, the research defends that the game used is a funny educational activity capable of modifying the children's environment design from a multidimensional perspective that considers the environment as a complex system, sensibilizing the student to lay more values on the environment in which they live.

Key words: Pedagogic game; Teacvhing Sciences; Enviromental education; Ludic methodologies.

\section{Introdução}

A degradação da natureza, a ameaça à biodiversidade, o aquecimento desordenado do planeta, a poluição de rios e mares provocaram na humanidade uma nova maneira de ser. Hoje, somos levados a acreditar que nossa participação individual no mundo é irrelevante, mas, na prática, nossas ações influem, e muito, em toda a dimensão planetária, pois vivemos em rede.

De uma perspectiva sócio-cultural, os problemas que afetam o nosso planeta, nos dias atuais, podem estar estreitamente relacionados com o elevado nível de exclusão social de grande parte da nossa população, já que são muitas as pessoas que não possuem acesso aos direitos constitucionais básicos, sejam eles de saúde, de educação, de segurança e até mesmo de acesso à informação sobre assuntos ligados ao meio em que vivem. Isso contribui para a formação de uma percepção de meio ambiente que exclui os seres humanos como indivíduos integrantes de todo a dinâmica da natureza.

Alterar esse quadro significa vencer o desafio apresentado para a nossa sociedade moderna. Construir tanto um local para se viver com maior justiça social quanto um ambiente sustentável requer ações efetivas relacionadas à Educação Ambiental.

Nesse sentido, a Educação Ambiental se apresenta como uma relevante alternativa na busca de construirmos um mundo mais consciente, devido ao seu caráter interdisciplinar, que colabora, de forma decisiva, para a mudança nos rumos da educação e, por conseguinte, do mundo que estamos construindo, cheio de inovações que emergem a cada segundo, de modo a facilitar, e melhorar, a existência do ser humano na Terra.

A escola, portanto, torna-se um local propício para o trabalho dos temas relativos à Educação Ambiental, pois configura-se como um espaço privilegiado para se propor mudanças, já que os hábitos de crianças e adolescentes não estão tão consolidados como os dos adultos.

Instigadas pelas relações sociais ou por fatores naturais, por necessidade, interesses, vontade e coerção, as pessoas aprendem o tempo todo. Aprendem relacionar-se com outras pessoas e a conviverem com seus próprios valores e sentimentos (DELIZOICOV et al, 2009, p. 123). 
Nesse sentido, a escola exerce, ou deveria exercer, um papel fundamental na construção do conhecimento para a formação de indivíduos críticos com relação à estrutura econômica, política e social, e conscientes de sua cidadania, a fim de que possam tornar-se agentes de transformação da sociedade (ABIDALA, 1996, p. 25).

A Educação Ambiental deve, pois, ser organizada de forma a proporcionar oportunidades, para que todos utilizem o conhecimento objetivando a compreensão da realidade e nela atuarem. Krasilchik \& Marandino (2007, p. 10) nos atentam para o fato de que é necessário que os docentes mudem de postura na preparação de seu trabalho, o qual deve levar à crescente participação dos alunos em questões que afetam o seu modo de vida e que demandam a contribuição de diferentes capacidades para análise e tomada de decisões.

Estratégias didáticas voltadas para o ensino fundamental as quais podem despertar no educando o interesse e a participação nas aulas são pontos-chaves para a incorporação dessas novas atitudes no cotidiano dos alunos. Com isso, materiais didático-pedagógicos que auxiliem o educador a trabalhar os temas de Educação Ambiental de maneira lúdica são fundamentais dentro do ambiente escolar. Para Silva (2008, p.14), os jogos didáticos possuem uma função importante no processo educacional. Os ensinamentos transmitidos ludicamente são absorvidos e assimilados pelos alunos com maior facilidade. Portanto, cabe, ao professor, (re) significar sua prática docente para, com a qual, contribuir para a profissionalização do seu trabalho docente (PEREIRA, 2010, p. 26).

Então, o objetivo deste artigo é propor, e avaliar, um jogo de trilha ecológica para trabalhar os temas de Educação Ambiental com alunos do ensino fundamental de uma escola pública do município de Vitória de forma contextualizada com sua realidade. Esse recurso didático pretende auxiliar o educador no despertar o interesse dos educandos sobre o tema, e incentiválos a perceberem que também fazem parte do meio em que vivem e que qualquer alteração provocada pode trazer sérios danos para a sobrevivência dos diferentes seres vivos que habitam o planeta.

\section{Fundamentação teórica}

A expressão Educação Ambiental compõe-se de um substantivo e um adjetivo, que envolvem, respectivamente, o campo da Educação e o campo Ambiental. Enquanto o substantivo Educação confere a essência do vocábulo "Educação Ambiental", definindo os próprios fazeres pedagógicos necessários a esta prática educativa, o adjetivo ambiental anuncia o contexto desta prática educativa, ou seja, o enquadramento motivador da ação pedagógica (BRASIL, 2004, p. 7).

Tozoni-Reis (2003 apud PEREIRA, 2010, p. 11) defende que a Educação Ambiental aponta para um processo de construção da relação humana com o ambiente onde os princípios da responsabilidade, da autonomia, da democracia, entre outros, estejam sempre presentes. Esta 
concepção muito de perto dialoga com a de Loureiro (2004), para quem a Educação Ambiental deve ser realizada pela articulação dos espaços formais e não formais de educação; pela aproximação da escola com a comunidade em que e insere e atende; pelo planejamento integrado de atividades curriculares e extracurriculares; pela construção coletiva e democrática do projeto político-pedagógico e pela vinculação das atividades de cunho cognitivo com as mudanças das condições objetivas de vida.

Todas as recomendações, decisões e tratados internacionais sobre o tema Meio Ambiente evidenciam a importância atribuída por lideranças de todo o mundo para a Educação Ambiental como abordagem indispensável para conseguir criar, e aplicar, formas mais sustentáveis de interação entre a sociedade e a natureza e soluções para os problemas ambientais. Evidentemente, a educação sozinha não é suficiente para mudar os rumos do planeta, mas certamente é condição necessária para isso (BRASIL, 1998).

De acordo com os Parâmetros Curriculares Nacionais (PCNs) do Ministério da Educação (BRASIL, 1998), a preocupação em relacionar a educação com a vida do aluno - seu meio, sua comunidade - não é novidade. Ela vem crescendo especialmente desde a década de 60 no Brasil. Exemplo disso são atividades como os "estudos do meio". Porém, a partir da década de 70, com o crescimento dos movimentos ambientalistas, passou-se a adotar explicitamente a expressão "Educação Ambiental" para qualificar iniciativas de universidades, escolas, instituições governamentais e não governamentais, por meio das quais se busca conscientizar setores da sociedade para as questões ambientais. Um importante passo foi dado com a Constituição de 1988, quando a Educação Ambiental se tornou exigência a ser garantida pelos governos federal, estaduais e municipais (artigo 225, §10, VI).

Fourez (1995) nos atenta para o fato de que, ao adotar determinada tecnologia, estamos adotando determinado modelo de sociedade. Observamos, então, que a abrangência dos debates que envolvem meio ambiente é amplo e evoca mudança cultural, tomada de consciência sobre determinada questão, consciência essa que só é possível por meio da assimilação de novos conceitos. Guimarães (1998, p. 51), ao justifica a inserção de temas referentes à educação ambiental no âmbito escolar,

Pela premente necessidade de se levar ao âmbito escolar a discussão ser humano/ ambiente, não apenas pela inclusão legal dessa temática no currículo escolar, mas pela efervescência do tema na sociedade, como também pela realidade do desajuste do mundo moderno, justifica - se a implantação da Educação Ambiental na rede escolar (GUIMARÃES, 1998, p. 51).

Portanto, é necessário que o educando atribua significado ao debate abordado na escola e compreenda as concepções e conceitos apresentadas pela Educação Ambiental, vez que estes 
estão ligados, e atuantes, no seu cotidiano. Só por meio dessa percepção e aceitação é que os conceitos que norteiam o debate atual em Ciência, Tecnologia e Sociedade serão passíveis de aceitação e contarão com a participação da sociedade.

"Com o passar do tempo a humanidade vai afirmando uma consciência individual. Paralelamente, cada vez mais vai deixando de se sentir integrada com o todo e assumindo a noção de parte da natureza. Nas sociedades auaís o ser humano afasta - se da natureza. A individualização chegou ao extremo do individualismo. $O$ ser humano, totalmente desintegrado do todo, não percebe mais as relações de equilíbrio da natureza. Age de forma totalmente desarmônica sobre o ambiente, causando grandes desequilíbrios ambientais" (GUIMARÃES, 1998, p.12).

Cabe ressaltar, também, que, tradicionalmente, segundo Pereira (2010, p. 27), no ensino de Ciências a abordagem de temas sobre o meio ambiente é realizada nas seções relacionadas à Ecologia. Nesse caso, os livros incentivam aos educandos a desenvolverem uma postura de conservação, uso e manejo correto do ambiente, ou seja, destacam-se assuntos associados basicamente a conhecimentos biológicos/ecológicos. Para o autor, às vezes, o meio ambiente é apresentado como sendo a natureza para apreciação e preservação, somente.

Entretanto, é importante salientar que a Educação Ambiental não se restringe ao ensino de Ecologia e ao ensino de Ciências, também não se caracteriza como um doutrinamento para modificar comportamentos ambientais predatórios (TOZONI-REIS, 2003 apud PEREIRA, 2010, p. $11)$.

Segundo Pereira (2010, p. 33-34) são muitas as concepções sobre o meio ambiente que aparecem nos livros didáticos. Entre elas consta a concepção ambiental generalizante, como sendo a que define meio ambiente de forma ampla, vaga e abstrata; a naturalista, que trata o meio ambiente como sinônimo de natureza e como o lugar onde os seres vivos habitam, bem como enfatiza os fatores bióticos e abióticos na composição do meio; a biocêntrica, a que aparece quando, no repertório conceitual, considera-se o ser humano como mais um ser vivo que se encontra inserido no meio ambiente, sem que este, necessariamente, tenha utilidade para o homem. A concepção Antropocêntrica também aparece e é caracterizada quando a razão de ser do meio ambiente é considerada como a serviço do homem e de sua existência. Outra concepção é a multidimensional, que considera o meio ambiente como um sistema complexo, resultante da interação entre fatores diversos como os biológicos, físicos, químicos, culturais, históricos, políticos, econômicos, numa configuração em constante mudança.

Entretanto, esse tipo de abordagem, apesar de ter uma maior aproximação com a realidade natural, é a menos observada nas pesquisas atuais sobre a temática em questão. Dessa forma, é fundamental que a educação ambiental proposta em um ambiente escolar busque 
transformar as concepções dos alunos sobre o meio ambiente, transformando as representações sociais equivocadamente construídas pelos livros e manuais didáticos de ciências.

\section{Percurso metodológico}

\subsection{A pesquisa}

Pesquisa de natureza qualitativa que propõe apresentar, e avaliar, o Jogo "Trilha Ecológica Capixaba" como atividade lúdica de Educação Ambiental, no ensino fundamental, por meio de um estudo de caso (LUDKE \& ANDRÉ, 1986). na coleta de dados adotou-se uma postura de observação participante e sistemática dos procedimentos, durante a trilha; a análise dos conteúdos foi baseada em Bardin (2004).

\subsection{Local}

A escola escolhida para a realização das atividades fica localizada no bairro Santa Martha, em Vitória (ES). Atende a alunos do primeiro ano do ensino fundamental até educando do nono ano do ensino fundamental. Pertence à rede municipal de ensino de Vitória, capital do Estado. Funciona nos turnos matutino e vespertino e fica localizada no ambiente urbano, próximo de muitas residências e de um comércio bastante movimentado. Além disso, recebe alunos de diversas classes sociais, predominando crianças de pouco poder econômico.

\subsection{Sujeitos}

A turma analisada possui um total de 29 alunos frequentando regularmente as aulas, sendo que $44,82 \%$ dos discentes são do sexo feminino e $55,18 \%$ são do sexo masculino.

A faixa etária dos educandos dessa turma analisada variou dos 10 aos 14 anos de idade.

Vale ressaltar que, no dia da realização do jogo, 21 alunos estavam presentes e a tarefa foi trabalhada em uma aula com duração de cinquenta minutos.

\subsection{Coleta de dados}

Foram feitas observações dos educandos durante a realização das atividades, e a análise das percepções dos alunos sobre o recurso didático foi feita em uma linha fenomenológica, aqui compreendida como "um procedimento para obter dados que deverão ser analisados e interpretados fenomenologicamente, visando à busca da essência e de sua transcendência, postas em termos textuais" (BICUDO, 2000, p. 75). Três momentos fundamentam uma investigação fenomenológica: o olhar atentivo para o mostrar-se do fenômeno, o descrever o 
fenômeno e o não se deixar levar pelas crenças pré-estabelecidas sobre a realidade do fenômeno (ROJAS et al., 2012).

$\mathrm{Na}$ obtenção de dados na investigação fenomenológica são considerados o sujeito da pesquisa e os próprios investigadores. O fenômeno manifesta-se sob diferentes perspectivas e o sujeito descreve o que lhe é percebido como modo de obtenção de dados. Segundo Bicudo 2000), a Fenomenologia trabalha com os dados fornecidos pela descrição e vai além, analisando-os e interpretando-os.

\subsection{0 jogo}

O jogo é do tipo tabuleiro e possui uma trilha ecológica (Figura 1) com uma foto de fundo de um dos cartões postais da divisa das cidades de Vitória e de Vila Velha (ES), a Terceira Ponte. Dessa forma, a trilha ecológica oferecida aos alunos "acontece"dentro do ambiente urbano. Tivemos dois intuitos em construir a trilha ecológica dentro da cidade, quais sejam, primeiro fazer os alunos refletirem que fazem parte meio ambiente e que suas ações podem provocar impactos positivos e negativos ao meio. Segundo, pretendíamos contextualizar o jogo com a realidade do educando, facilitando a apropriação dos conhecimentos e despertando o interesse na mudança de postura que transforme as atitudes do educando para um mundo mais sustentável.

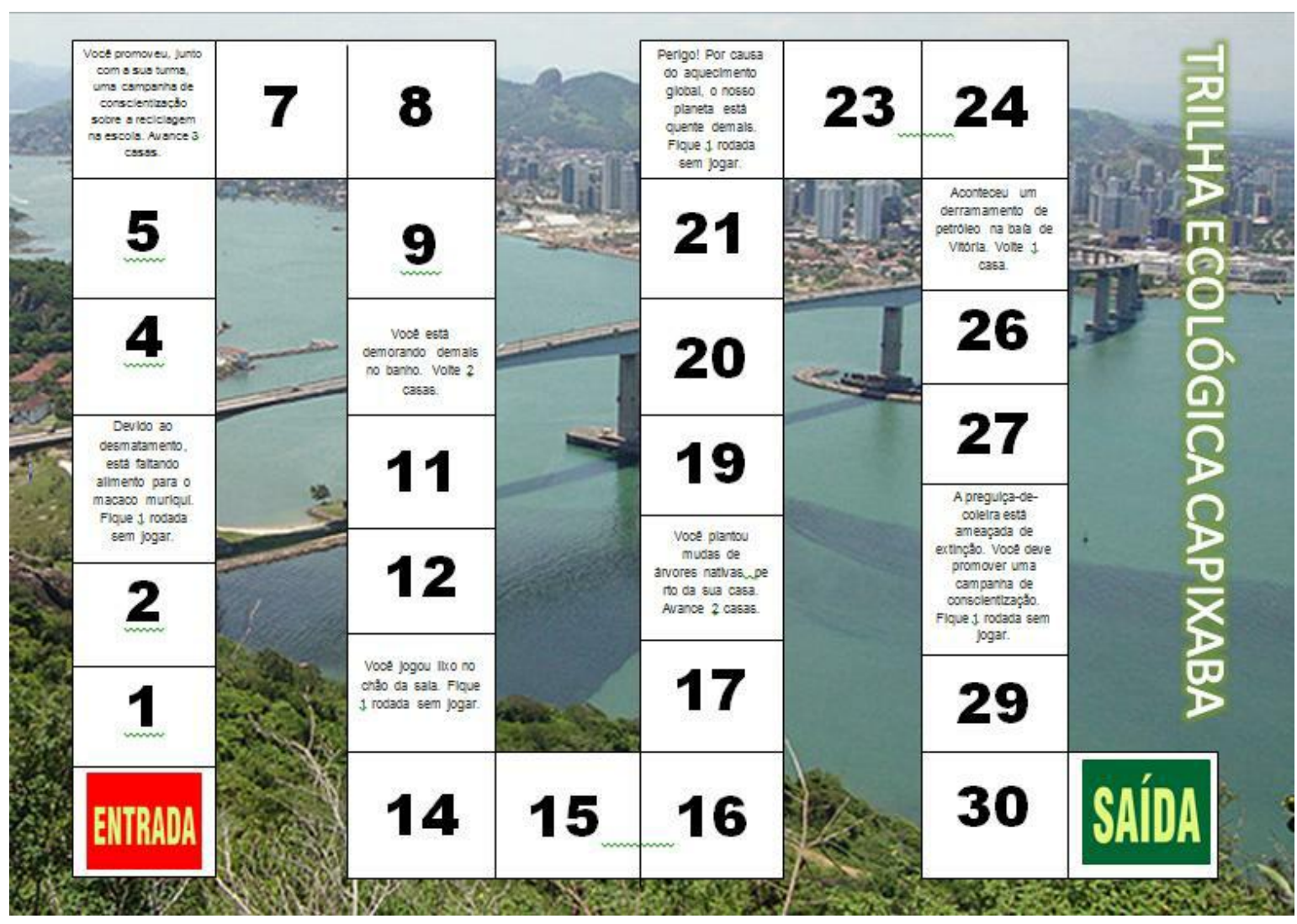

Figura 1: Jogo "Trilha ecológica capixaba" 
O Jogo de tabuleiro "Trilha Ecológica Capixaba" pode compartilhado jogado por no mínimo dois alunos e, no máximo, quatro. É composto por um dado de seis faces, quatro marcadores de cores diferentes (Figura 2) e 30 espaços numerados, alguns deles com situações ocorridas ou que poderão ocorrer no meio ambiente da região metropolitana da Grande Vitória, sejam elas de preservação ou de degradação do meio natural. Cada vez que o jogador parar em uma dessas casas que possuem essas informações, algum tipo de prenda ou de benefício para o jogo será concedido ao participante.

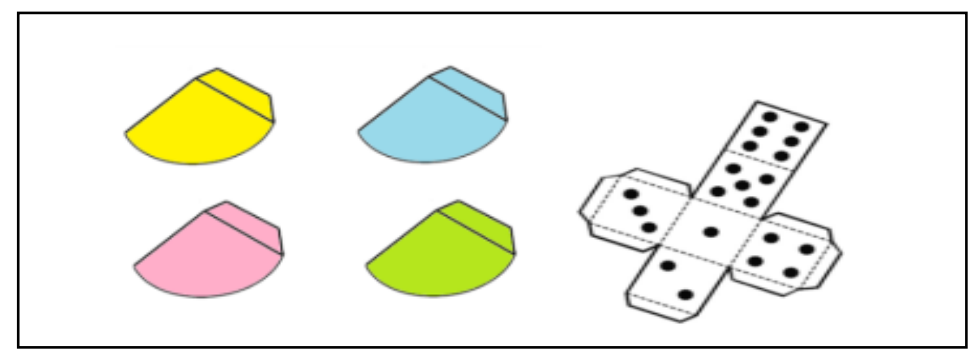

Figura 2: Peões e dado de 6 lados utilizados no Jogo.

O jogo consiste em uma trilha dividida em casas, cada qual composta ou pela sequência numérica das casas ou por um texto que deve ser lido e a ação proposta realizada. Após jogar o dado, o aluno jogador deve movimentar o pino contando o número de segmentos correspondente ao número obtido no dado. Será o vencedor do jogo o aluno que primeiro atingir o fim da trilha.

Por se tratar de um jogo para alunos do ensino fundamental, suas regras foram elaboradas de forma muito simples. Isso, porque quando o aluno não compreende as regras, ele perde o interesse pelo jogo, por isso estas devem ser bem claras e sem muita complexidade nessa faixa etária, a fim de motivar o estudante, buscando seu interesse pelo desafio e pelo desejo de participar da atividade proposta.

\section{Análise da atividade}

Durante o trimestre letivo (primeiro trimestre de 2012), os alunos participaram de aulas teóricas sobre o tema Meio Ambiente na disciplina de Ciências. Além disso, vários recursos metodológicos foram empregados para trabalhar o assunto (vídeos, pesquisas na Internet, filmes, entre outros). Para a aplicação do jogo "Trilha Ecológica Capixaba", os alunos foram divididos em grupos de dois, três ou quatro educandos cada. As equipes recebeu um tabuleiro com o jogo da trilha, um dado e peões de cores distintas para a identificação do jogador. O professor regente da turma, após a entrega do material, explicou detalhadamente sobre as regras do jogo e, posteriormente, autorizou o início da atividade. Cada equipe jogou em média cinco rodadas (Figura 3). 
A atividade foi bastante atrativa e envolveu demais os alunos no processo de ensino e de aprendizagem. As crianças ficaram muito empolgadas com o jogo da trilha.

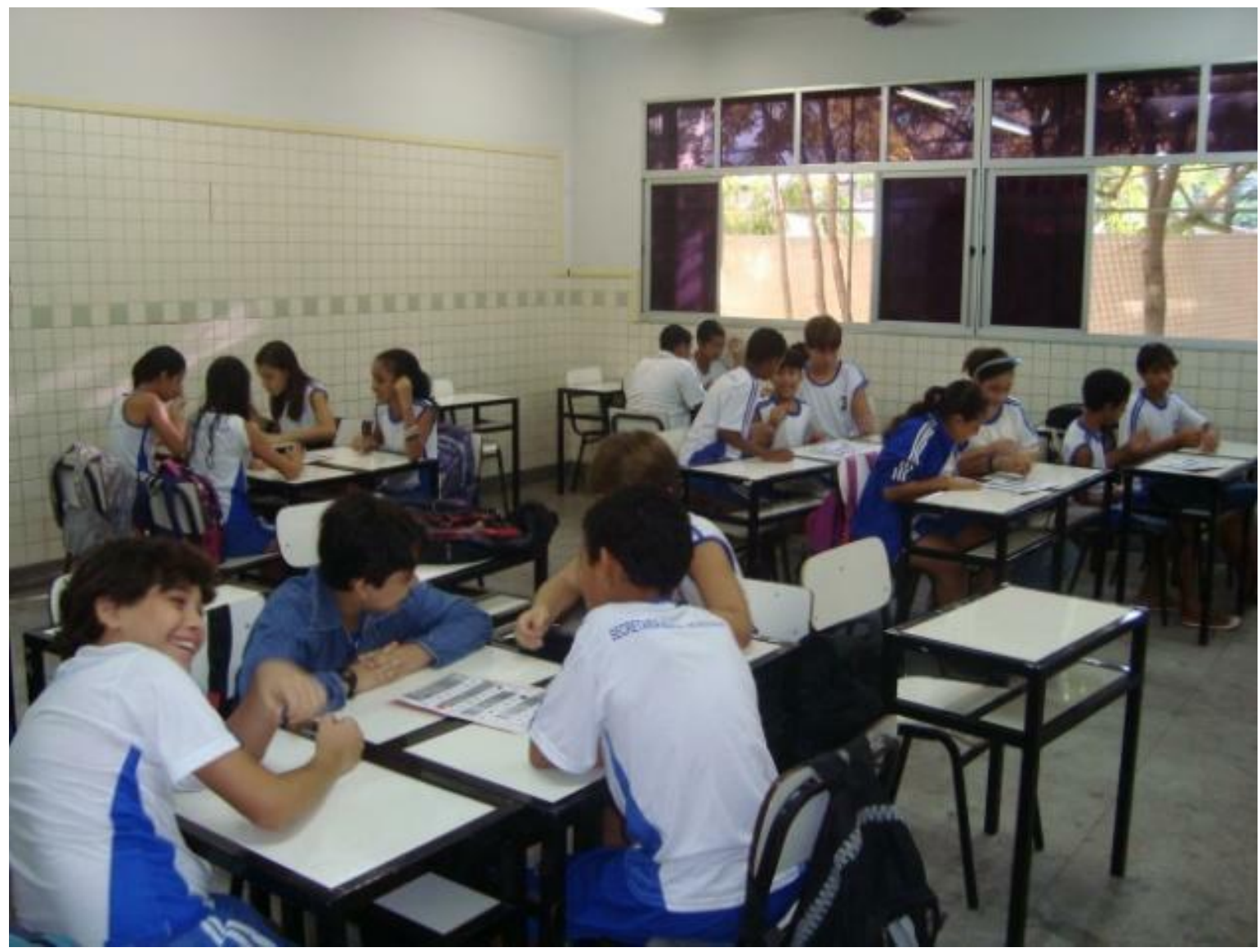

Figura 3: Alunos do sexto ano do ensino fundamental jogando "Trilha Ecológica Capixaba"

Percebemos que os estudantes logo tiveram um impacto inicial ao começar a aula com uma atividade nova, ou seja, uma metodologia diferente da tradicionalmente utilizada (com livros didáticos, quadro branco e pincel). Observamos que o primeiro impacto dos alunos ao receberem o jogo foi estranhar o fato de ganharem um jogo intitulado trilha ecológica contendo como fundo a fotografia de sua cidade. Isso causou certa novidade e expectativa para as crianças, principalmente quando observamos as falas de algumas delas, conforme descritas no quadro abaixo (quadro 1):

Quadro 1: Descrição das falas de alguns educandos ao receberem o jogo

Criança 1: "Nossa, não sabia que o meio ambiente estava dentro da cidade".

Criança 6: "Que estranho, uma trilha da natureza dentro da cidade!".

Existe a necessidade de se considerar, como ponto de partida para se trabalhar a temática ambiental, aspectos e elementos do ambiente natural, social e cultural dos alunos, bem como suas representações e saberes espontâneos sobre o tema (PEREIRA, 2010, p. 33).

R. B. E. C. T., vol 6, núm. 2, mai-ago.2013 ISSN - 1982-873X 
Muitos, ao estudarem os temas de Ecologia, ficam com a ideia de que a natureza está separada do meio urbano, o local que moramos. Isso foi um passo importante para a primeira indagação e quebra de alguns conhecimentos prévios que os alunos trazem sobre esse aspecto. Para Delizoicov et al (2009, p. 131), o professor pode aprofundar a compreensão de seus alunos sobre a natureza do conhecimento científico, iniciando pelo resgate e problematização da concepção que possuem.

Outro fato que chamou bastante a atenção das crianças foi o fato de que certos números da trilha continham prendas ou benefícios, dependendo do tipo de acontecimento que havia em cada uma. Quando era algo que favorecia o meio ambiente, algum benefício era concedido ao jogador, o que era motivo de muita torcida por parte das crianças para tirarem um número que parasse nesses lugares do jogo. Vale ressaltar que muitos desses acontecimentos estavam relacionados com a cidade que os alunos residem, sejam eles por necessidades que qualquer ambiente precisa (limpeza, reciclagem e coleta seletiva), ou até mesmo relacionava aspectos ecológicos e comportamentais sobre os animais típicos da região, como hábitat e nicho ecológico.

Pela forma como os alunos participaram da atividade e debateram sobre as questões presentes no jogo, percebemos que a proposta conseguiu atingir seu objetivo principal, qual seja, levar a Educação Ambiental de forma mais lúdica para que os educandos percebessem que todos possuem responsabilidade com as questões relacionadas ao meio ambiente. Isso pode ser evidenciado através da observação do discurso de alguns discentes ao final da atividade (Quadro 2).

Quadro 2: Falas de alguns alunos após a realização da atividade

Criança 3: "Muito legal participar de um joguinho e aprender mais sobre o lugar onde moramos".

Criança 10: "Gostei de jogar essa trilha. Com ela, pude perceber que a escola é um meio ambiente também e por isso precisamos deixá-la limpa para não aparecer animais que trazem doenças".

Criança 7: "Vou procurar não jogar mais lixo na rua e nem na escola na hora do recreio".

O professor, a partir dessa atividade, pode propor outras diferentes etapas com o mesmo jogo. Como exemplo, podemos citar que os alunos podem adaptar esse jogo para um campo mais específico do seu cotidiano, transformando as casas da brincadeira para as ruas do bairro em que residem e os problemas ambientais apresentados na trilha poderiam ser aqueles que acontecem com mais frequência no lugar que está inserida a escola. 


\section{Considerações finais}

Elaboramos uma atividade lúdica por meio de um jogo de tabuleiro, que trabalha a Educação Ambiental com alunos do ensino fundamental com o objetivo principal de modificar sua concepção de meio ambiente para uma perspectiva mais multidimensional, que considera natureza como um sistema complexo, resultante da interação entre fatores diversos como os biológicos, físicos, químicos, culturais, históricos, políticos, econômicos, numa configuração em constante mudança, sensibilizando o educando de forma que valorize mais o ambiente em que vive.

A escola é um local essencial para a democratização dos conhecimentos e a inserção de indivíduos mais críticos na sociedade. É necessário fomentar um ensino de Ciências que prepare os cidadãos para lidarem com responsabilidade com as questões sociais, ambientais, econômicas, ecológicas, entre outras relativas à ciência. Além disso, essa proposta de atividade pode fazer parte sequências didáticas de educadores comprometidos em levar a Educação Ambiental de maneira significativa para os seus educandos.

Acreditamos que a mudança para um mundo mais sustentável só será possível se perpassada pela escola, sendo que essa precisa de urgentes mudanças no âmbito de formação de professores inicial e continuada, mudanças no currículo, desenvolvimento de novos materiais de ensino, entre outros, que, associados à inserção de novas metodologias poderão, aos poucos, inserir a educação em um novo momento, em que se fomente nas escolas a Educação Ambiental com a devida atenção para que essa não se torne reducionista como temos observado, sendo repleta de discursos midiáticos, visto o modismo dos temas ecológicos. Nesse sentido, a Educação Ambiental que buscamos é aquela fundamentada nos pressupostos que buscam a mudança de comportamento, que busquem transformar as atitudes de preservação do meio ambiente em prática social, buscando contribuir para a construção de uma identidade cultural ecológica do discente de forma que este já não consiga mais dissociar as práticas de educação ambiental do seu dia a dia. A escola, por sua natureza sócio-cultural possui papel relevante na construção dessa subjetividade. Está posto o desafio. 


\section{Referências}

ABIDALA, M. G. Educação Popular na América Latina: Experiência do Brasil. Vitória: UFES, 1996.

BARDIN, L. Análise de conteúdo, 3ạ. Edição, Lisboa: Edições 70, 2004.

BICUDO, M. A. V. A contribuição da fenomenologia à educação. In: BICUDO, M. A. V.;

CAPPELLETTI, I. F. (Org.) Fenomenologia: uma visão abrangente da educação. São Paulo: Olho d"Água, 1999, p. 11-51.

BRASIL. Constituição (1988). Constituição da República Federativa do Brasil. Brasília, DF, Senado, 1998.

BRASIL, Ministério da Educação o do Desporto. Parâmetros Curriculares Nacionais: Temas transversais. Brasília: MEC/SEF, 1998.

BRASIL, Ministério do Meio Ambiente. Diretoria de Educação Ambiental. Identidades da Educação Ambiental Brasileira. Brasília: MMA, 2004.

DELIZOICOV, D; ANGOTTI, J. A. PERNAMBUCO M.M. Ensino de Ciências: Fundamentos e Métodos. 3ạ edição. São Paulo: Cortez, 2009.

FOUREZ, G. A Construção das Ciências: Introdução à Filosofia e à Ética das Ciências. São Paulo: Editora da UNESP, 1995.

GUIMARÃES, M. A dimensão ambiental na educação. 2ª ed. São Paulo: Papirus, 1998.

KRASILCHICK, M; MARANDINO, M. Ensino de Ciências e Cidadania. 2a ed. São Paulo: Editora Moderna, 2007.

LOUREIRO, B. F. C. Educação, ambiente e sociedade. Problematizando conceitos em Educação Ambiental. Serra: Companhia Siderúrgica de Tubarão. 2004.

LÜDKE, M. e ANDRÉ, M. E. D. A. Pesquisa em educação: abordagens qualitativas. São Paulo: EPU, 1986.

PEREIRA, M. G. Pelas ondas do saber: Conhecer, agir e transformar o ambiente. Ciências: ensino fundamental , Antônio Carlos Pavão. Brasília: Ministério da Educação, Secretaria de Educação Básica. v.18, 2010. 212 p

ROJAS, J.; BARUKI, R.F.; SOUZA, R. S.E. Fenomenologia e rigor na pesquisa educacional: a experiência da UFMS. Anais do IV SIPQ, 2012 p. 1-10

SILVA, R M. L. Ciência Lúdica: Brincando e aprendendo com jogos sobre ciências. Salvador: Edufbar, 2008. 
Leonardo Salvalaio Muline -Instituto Federal do Espírito Santo - IFES Vitória - ES leomuline@hotmail.com

Adriane Gonçalves Gomes - Instituto Federal do Espírito Santo - IFES Vitória - ES adrianegoncalvesgomes@yahoo.com.br

Manuella Villar Amado - Instituto Federal do Espírito Santo - IFES Vitória - ES manuellaamado@gmail.com

Carlos Roberto Pires Campos - Instituto Federal do Espírito Santo - IFES Vitória- ES carlosr@ifes.edu.br 